\title{
AWARENESS REGARDING HEALTH EFFECTS OF PESTICIDES USE AMONG FARMERS IN A MUNICIPALITY OF RUPANDEHI DISTRICT
}

\author{
Gurung $\mathrm{S}^{1}$, Kunwar $\mathrm{M}^{2}$.
}

\begin{abstract}
INTRODUCTION:

Pesticides are natural or synthetic agents that are used to kill unwanted plant or animal pests. Pesticides use is the most attractive method of controlling pest which involves less labour and characterised higher outcome per hector of land. Extensive use of such pesticides results in substantial health and environmental threats.
\end{abstract}

\section{MATERIAL \& METHODS:}

Descriptive cross-sectional design was used for the study to find out awareness regarding health effects of pesticides use. Fifty vegetable farmers were selected as the study sample by non purposive and snow ball sampling technique. Pretested structured interview schedule was used for data collection and analyzed by using descriptive statistics.

\section{RESULTS:}

The findings of the study revealed that respondents were aware that skin irritation (96\%), dermatitis (92\%), dizziness (98\%), headache (96\%) as poisoning symptoms in skin and nervous system. Respondents were aware nausea (84\%), vomiting $(96 \%)$, dyspnoea $(88 \%)$, and throat itching $(76 \%)$ as poisoning symptoms in gastro-intestinal and respiratory system. Respondents were also aware that eye irritation (96\%) and burning $(90 \%)$, and tachycardia $(90 \%)$ as poisoning symptoms of pesticide use in eye and cardio vascular system. They were aware that use of pesticides may cause cancer (88\%), foetal death (74\%), infertility (66\%), birth defects (66\%) and miscarriage (56\%) as long term effects. Cent percent of respondents were aware that washing exposed part with soap water, taking bath and changing clothes asimmediate actions after pesticides contact with body

\section{CONCLUSION:}

Based on the findings of the study more than half of respondents had low level of awareness regarding health effects of pesticides use. So, it is recommended to organize awareness program to the farmers regarding health effects of pesticides use.

KEY WORDS: Health effects, pesticides use, farmer, poisoning symptoms

1. Associate Professor, Universal College of Nursing Sciences, UCMS, Siddarthnagar-1, Rupandehi, Nepal

2. Senior Staff Nurse, Gautam Buddha Community Heart Hospital, Ramnagar, Butwal-12, Rupandehi, Nepal

\author{
For Correspondence \\ Saraj Gurung \\ Associate Professor \\ Universal College of Nursing Sciences \\ UCMS, Siddarthnagar-1, Rupandehi, Nepal \\ Email: g.saraj@gmail.com
}




\section{INTRODUCTION}

The term pesticide is defined as any substance or mixture of substances intended for preventing, destroying or controlling any pest, including vectors of human or animal disease, unwanted species of plants or animals causing harm during or otherwise interfering with the production, processing, storage, transport or marketing of food, agricultural commodities, wood and wood products, or animal feedstuffs, or which may be administered to animals for the control of insects, arachnids or other pests in or on their bodies. ${ }^{1}$

The use of chemicals in modern agriculture has significantly increased productivity. But it has also significantly increased the concentration of pesticides in food and in our environment, with associated negative effects on human health. Annually there are dozens of million cases of pesticide poisonings worldwide. ${ }^{2}$ The WHO and the United Nations Environment Program estimate pesticide poisoning rates of 2- 3 per minute with approximately 20000 workers dying from exposure every year, the majority in developing countries. ${ }^{3}$

Exposure to pesticides results in acute and chronic health problems, ranging from temporary acute effects such as irritation of the eyes and excessive salivation to chronic diseases such as cancer and reproductive and developmental disorders. ${ }^{4}$

Studies have shown that $90 \%$ of the total pesticides are used in vegetable farming. So various studies in Nepal reported the massive use of chemical pesticides affects the human health as well as other ecological aspects such as soil surface and ground water, micro and macro flora and fauna.

\section{MATERIAL \& METHODS}

Descriptive cross-sectional design was used for study to find out awareness regarding health effects of pesticides use among farmers. The study was conducted in Tilottama municipality ward no. 24, Rupandehi. Fifty vegetable farmers who are owner of at least 0.0676 hectare $(2$ kathha) of agricultural land were selected as the study sample by non probability purposive and snow ball sampling technique. Interview method was used for data collection with use of pretested structured questionnaire, developed by researchers by reviewing the related literatures, consulting with the subject experts. There were 28 questions regarding health effects of pesticides use. Data collection was done in 2 weeks of period (August 14 to 27, 2016). Administrative and ethical approval was obtained from concerned authorities prior to data collection.

The researchers contacted each respondent and obtained written informed consent for the study and interviewed.
Researchers interviewed five to six respondents per day and only one farmer was included in the study from one household. Descriptive statistical method was used with SPSS 16 version to analyze data using frequency, percentage and mean.

\section{RESULTS}

Mean age of the respondents' was 33.5 years. Eighty percent of respondents were Madhesi and among 50 respondents 94\% were literate. Regarding cultivable land, $94 \%$ of respondents had 2-11kattha cultivable land. As regards awareness on vulnerable people of pesticides use, all of the respondents answered those who apply the pesticides and 16\% answered those who purchase the pesticides. Similarly, all and $68 \%$ of respondents answered pregnant women and elderly as more vulnerable people of pesticides use (Table 1).

Table 1: Respondents' Awareness Regarding Vulnerable and More Vulnerable People of Pesticides Use

\begin{tabular}{lcc}
\hline Responses** & Frequency & Percentage \\
\hline Vulnerable people & 50 & 100 \\
Those who apply the pesticides* & 42 & 84 \\
Those who work on the farm* & 46 & 92 \\
Those who consume the crops* & 21 & 42 \\
Those who live near the farm area* & 8 & 16 \\
Those who purchase the pesticides & 50 & 100 \\
More vulnerable people & 48 & 96 \\
Pregnant women* & 34 & 68 \\
Children* & - & - \\
Elderly* & Mean \% score of vulnerable people $=79.5$ \\
Adult & Mean \% score of more vulnerable people $=88$ \\
** Multiple response & correct response
\end{tabular}

As regards awareness on poisoning symptoms of pesticides use in skin $96 \%$ and $22 \%$ of respondents answered skin irritation and crust formation. Similarly, $98 \%$ and $22 \%$ of respondents answered dizziness and pallor as poisoning symptoms of pesticides use in nervous system (Table 2).

Table 2: Respondents' Awareness Regarding Poisoning Symptoms of Pesticides Use in Skin and Nervous System

\begin{tabular}{lcc}
\hline Responses** & Frequency & Percentage \\
\hline Skin & 46 & 92 \\
Dermatitis* & 30 & 60 \\
Blister* & 48 & 96 \\
Skin irritation* & 11 & 22 \\
Crust formation & 32 & 64 \\
Pruritis* & & \\
Nervous system & 49 & 98 \\
Dizziness* & 48 & 96 \\
Headache* & 27 & 54 \\
Weakness* & 11 & 22 \\
Pallor & 26 & 52 \\
Numbness* & &
\end{tabular}

**Multiple response *Correctresponse 
Regarding poisoning symptoms of pesticides use in gastrointestinal system,96\% and $14 \%$ of respondents answered vomiting and heartburn. Similarly, $88 \%$ and $50 \%$ of respondents answered dyspnoea and chest pain as poisoning symptoms of pesticides use in respiratory system (Table 3).

Table 3: Respondents' Awareness Regarding Poisoning Symptoms of Pesticides Use in Gastro-intestinal System and Respiratory System

$$
n=50
$$

\begin{tabular}{lcc}
\hline Responses** & Frequency & Percentage \\
\hline Gastro-intestinal system & & \\
Diarrhoea* & 31 & 62 \\
Heartburn & 7 & 14 \\
Vomiting* & 48 & 96 \\
Nausea* & 42 & 84 \\
Respiratory system & & \\
Chest pain* & 25 & 50 \\
Cough* & 26 & 52 \\
Dyspnoea* & 44 & 88 \\
Throat itching* & 38 & 76 \\
**Multiple response $\quad$ Mean \% score of poisoning symptoms in GI system $=80.67$ \\
*Correct response $\quad$ Mean \% score of poisoning symptoms in respiratory system $=66.5$
\end{tabular}

As regards awareness on poisoning symptoms of pesticides use in eye $96 \%$ and $20 \%$ of respondents answered eye itching and blurred vision. Similarly, $90 \%$ and $4 \%$ of respondents answered tachycardia and cyanosis as poisoning symptoms of pesticides use in cardiovascular system (Table 4).

Table4: Respondents' Awareness Regarding Poisoning Symptoms of Pesticides Use in Eye and Cardiovascular System

\begin{tabular}{lcc}
\hline Responses** & Frequency & Percentage \\
\hline Eye & & \\
Eye itching* & 48 & 96 \\
Eye swelling & 22 & 44 \\
Eye burning * & 45 & 90 \\
Blurred vision* & 10 & 20 \\
Cardiovascular system & & \\
Palpitation* & 21 & 42 \\
Tachycardia* & 45 & 90 \\
Cyanosis & 2 & 4 \\
Arrythmia* & 27 & 54 \\
\hline
\end{tabular}

**Multiple response Mean \% score of poisoning symptoms in eye $=68.67$ *Correct response Mean \% score of poisoning symptoms in cardiovascular system $=62$

As regards awareness on long term effects of pesticides use, $84 \%$ and $22 \%$ answered cancer and dizziness (Table 5).
Table 5: Respondents' Awareness Regarding Long Term Effects of Pesticides Use

$\mathrm{n}=50$

\begin{tabular}{lcc}
\hline Responses** & Frequency & Percentage \\
\hline Cancer* & 42 & 84 \\
Parkinson's disease* & 28 & 56 \\
Infertility* & 33 & 66 \\
Birth defects* & 33 & 66 \\
Foetal death* & 37 & 74 \\
Miscarriage* & 28 & 56 \\
Dizziness & 11 & 22 \\
\hline **Multiple response & \multicolumn{2}{c}{$*$ Correct response } \\
Mean \% score of long term effects of pesticide $=67$
\end{tabular}

As regards awareness on immediate actions after pesticides contact with body, all of respondents had answered washing the exposed part with soap and water, taking bath andchanging clothes (Table 6).

Table 6: Respondents' Awareness Regarding Immediate Action after Pesticides Contact with Body

\begin{tabular}{lrc}
\hline Responses** & Frequency & Percentage \\
\hline Washing the exposed part with soap and water* & 50 & 100 \\
Taking bath* & 50 & 100 \\
Changing clothes* & 50 & 100 \\
Do nothing & - & - \\
\hline
\end{tabular}

**Multiple response $\quad *$ Correct response Mean \% score $=100$

On the basis of mean awareness score $(19,473)$ of the study, $56 \%$ of respondents had low awareness regarding health effects of pesticides use (Table 7).

Table 7: Respondents' Overall Awareness Regarding Health Effects of Pesticides Use

\begin{tabular}{lcc}
\hline Level of awareness & Frequency & Percentage \\
\hline High awareness & 22 & 44 \\
Average awareness & - & - \\
Low awareness & 28 & 56 \\
\hline
\end{tabular}

\section{Mean awareness score $=19.473$}

\section{DISCUSSION}

The findings of the study revealed that $100 \%$ of respondents knew that people who apply the pesticides, $92 \%$ knew who consume the crops, $84 \%$ knew who work on the farm and $42 \%$ knew who live near farm area are vulnerable of pesticides use. Findings are not consistent with the study ${ }^{6}$ which shows $81.3 \%$ had awareness regarding those who apply the pesticides, $60.7 \%$ about those who consume the crops, $70.5 \%$ 
about those who work on the farm and $26.8 \%$ about those who live near the farm area. Ninety-six percent of the respondents knew skin irritation as poisoning symptoms of pesticides use which is not consistent with the study ${ }^{7}$ which shows $66 \%$ of the respondents had awareness regarding skin irritation. The findings of the study showed that $98 \%$ and $96 \%$ of the respondents knew dizziness and headache as poisoning symptoms of pesticides use in nervous system. The findings of the study are not consistent with the study ${ }^{7}$ which shows $49 \%$ had awareness regarding dizziness and 66\% about headache. Eighty four percent of respondents were aware nausea as poisoning symptoms of pesticides use in gastro-intestinal system which is not consistent with the study ${ }^{7}$ which shows $34 \%$ had awareness regarding nausea.

Fifty percent, $52 \%, 88 \%$ and $76 \%$ of the respondents were aware that chest pain, cough, dyspnoea and throat itching respectively as poisoning symptoms of pesticides use in respiratory systems which are not consistent with the study ${ }^{7}$ which shows $35 \%$ had awareness regarding chest pain, 34\% about cough, $40 \%$ about dyspnoea and 54\% about throat itching. The findings of the study showed that $96 \%$ of the respondents knew eye itching and 20\% blurred vision as poisoning symptoms of pesticides use in eye. The findings of the study are not consistent with the study ${ }^{7}$ which shows $61 \%$ had awareness regarding eye itching and $42 \%$ about blurred vision. Sixty-two percent and $67 \%$ of the respondents knew poisoning symptoms of pesticides use in cardio-vascular system and long term effects of pesticides use. Cent percent respondents were aware that washing the exposed part with soap and water and changing clothes as immediate action after pesticides contacts with body which are not consistent with the study ${ }^{8}$ which shows $33 \%$ and $10 \%$ had awareness regarding washing the exposed part with soap and water and changing clothes as immediate actions after contact of pesticides with body.

The findings of the study showed that $56 \%$ of respondents had low awareness regarding health effects of pesticide use which is not consistent with the study ${ }^{9}$ which shows $93 \%$ of the farmers had unawareness regarding health effects of pesticides use.

\section{CONCLUSION}

Respondents have awareness that use of pesticides causes adverse effects on human health. Respondents are aware that vulnerable people and more vulnerable people of pesticides use. They are aware that skin irritation, dermatitis, dizziness, headache, nausea, vomiting, dyspnoea, throat itching, eye irritation and burning, and tachycardia are poisoning symptoms of pesticide use. They are aware that use of pesticides may cause cancer, infertility, miscarriage, birth defects and foetal death as long term effects. All of them are aware that immediate actions after pesticides contact with body. Besides this, more than half of respondents have low awareness regarding health effects of pesticides use in general.

\section{ACKNOWLEDGEMENT}

Researchers take this opportunity to extend sincere gratitude and thankfulness to all those who have contributed to complete this research study. We express our deep and sincere gratitude to all those experts for their valuable judgement, constructive feedbacks and enlightening suggestions throughout the study. This research would not have been completed without the immense support and cooperation of the respondents, so it is our deepest pleasure to thank them for their time and information needed for this research study.

\section{REFERNCES}

1. Kainga,E.P., Miller, A.T., \&Eipdi,T. Assessment of awareness of benefits and hazards posted by agricultural pesticides to farmers in selected communities of Bayelsa State, Nigeria. International Journal of Researcher in Agriculture and Forestry.2016;3(2): 3240.

2. Togo, D.Andersson, H.\&Treich, N. Pesticides and health: A review of evidence on health effects, valuation of risks, and benefit cost analysis. Adv Health Econ Health Serv Res. 2014; 24:203-95.

3. Kumari, L. P. \& Reddy, G. K. Knowledge and practice of safety use of pesticides among farm workers. IOSR Journal of Agriculture and Veterinary Sciences. 2013; 6(2): 01-08.

4. Grace, A.C., Muraleedharan, V. R., Swaminathan, T., \& Veerara ghavan, D. Use of pesticides and its impact on human health: a case of farmers in South India. IntJOccup Environ Health. 2006 Jul-Sep;12(3):228-33.

5. Sharma, R., Thapa, S., Manadhar, T., Shrestha \& Pradhan, S. Use of pesticide in Nepal and impacts on human health and environment. Journal of Agriculture an Environment, 2012; 13: $67-74$.

6. Pasiani, J. O., Torres,P., Silva, J. R.., Diniz,B. R. \& Caldas, E. D.. Knowledge, attitude and practice and biomonitoring of farmers and residents exposed to pesticides in Brazil. Environmental Reserach and Public Health. 2012; 9 (9): 3051-3068.

7. Lekei.E, Ngowi.A.V.\& London, L.Farmers'knowledge, practices and injuries associated with pesticides exposure in rural farming village in Tanzania. BMC Public Health 2014; 14:38-9

8. Gaber, S., \& Abdel, H.S. Effects of education and health locus pf control on safe use of pesticides: a cross sectional random study. Journal of Occupational Medicine and Toxicology 2012; 7:3-4.

9. Mokhele, A. T. Potential health effects of pesticide use on farm workers in Lesotho. South Africa Journal of Sciences. 2011;107:7-8. 